(Aus dem thierphysiologischen Laboratorium der landwirthschaftlichen Hochschule zu Berlin.)

\title{
Ueber Gesetzmässigkeit in der Ortsveränderung der Spermatozoen und in der Vereinigung derselben mit dem $\left.\mathbf{E i}^{1}\right)$. I.
}

Von

\section{J. Dewitz.}

\author{
Hierzu Tafel IV.
}

Obgleich die Wissenschaft den Vorgängen der Zeugung von jeher ein lebhaftes Interesse entgegengebracht hat, scheint man einem Gegenstande von allgemeiner Bedeutung wenig Beachtung geschenkt zu haben. Die Wissenschaft von der Zeugung gab nämlich bisher auf die Frage, wie es den Spermatozoen möglich ist mit dem Ei zusammenzutreffen, die wenig befriedigende Antwort, dass bei der Befruchtung eine so grosse Menge von Spermatozoen zur Verwendung komme, dass auch bei einer planlosen, nach keinen Gesetzen geregelten Ortsveränderung eines oder einige zu dem Bestimmungsort gelangten. Diese Antwort muss aber in solchen Fällen als ungenügend erachtet werden, wo den Spermatozoen Hindernisse entgegentreten, wie sie z. B. der lange Weg bei den Säugethieren oder gar die enge Oeffnung einer Mikropyle bietet. Ich habe monatelang beobachtet ${ }^{2}$ ), wie es dem Spermatozoon ohne sonstige Hülfe höchst selten gelingt, in eine enge Oeffnung hineinzutreffen.

Als das Erscheinen der Arbeit Pfeffer's ${ }^{3}$ ) die herrschende

1) Vgl. meine kurze Mittheilung "Ueber die Vereinigung der Spermatozoen mit dem $\mathrm{Ei}^{\prime \prime}$, dies. Archiv. 1885.

2) Diese Versuche wurden mit feinen Glascapillaren (vgl. Pfeffer), welche mit (wirkungsloser) Kochsalzlösung gefüllt waren, ausgeführt.

3) W. Pfeffer, Locomotorische Richtungsbewegung durch chemische Reize. Unters. a. d. bot. Inst. zu Tübingen. Bd. I, Heft 3, 1884. 
Ueber Gesetzmässigkeit in der Ortsveränderung der Spermatozoen etc. 359

Meinung, es bestehe in der Ortsveränderung keine Gesetzmässigkeit, wenigstens in ihrer Allgemeinheit beseitigte, fühlte ich mich in meiner Auffassung von der Sache bestärkt und wurde veranlasst, bei Thieren bezuigliche Beobachtungen anzustellen.

Meine Untersuchungen sind bis jetzt jedoch nur so weit gediehen, dass ich erst bei einem Thiere, bei Periplaneta (Blatta) orientalis, tiefer in die Verhältnisse eingedrungen bin. Es mögen nun vor der Hand diese Ergebnisse im Folgenden mitgetheilt werden.

Die Untersuchungen wurden in dem thierphysiologischen Laboratorium der landwirthschaftlichen Hochschule zu Berlin bei Herrn Professor Zuntz ausgefübrt. Derselbe hat mir trotz der unsichern Aussicht, die eine solche Arbeit bot, doch die Hülfsmittel des Instituts bereitwilligst zur Benutzung anvertraut und mich, wie auch sein Assistent, Herr Dr. Lehmann, auf das Freundlichste unterstitzt. Daher möchte ich den genannten Herrn hier meinen herzlichsten Dank aussprechen.

\section{Periplaneta orientalis.}

\section{Die Spermatozoen.}

Die Spermatozoen von P. orientalis, der grossen Küchenschabe, werden erhalten, indem man dem männlichen Thiere, welches sich vor dem Weibchen durch den Besitz langer Flügel auszeichnet, die letzten Leibesringe vom Körper abschneidet und an diesem abgeschnittenen Stück Bauch- und Rückenseite von einander trennt. Man nimmt dann sogleich ein weisses Packet, die männlichen Geschlechtsorgane ${ }^{1}$ ), wahr. Dieses Packet reisst man heraus, befreit es ohne Muihe von dem anhängenden Fett, den Tracheen u. s. w. und legt es in ein Uhrschälchen. Nachdem ein Tropfen Kochsalzlösung von der erforderlichen Concentration hinzugefiugt ist, wird die Masse mit einer feinen Scheere zerschnitten, bis man einen weissen Brei erhält. Wird dieser mit mehr Flüssigkeit zerrührt, so sinken die groben, nicbt zerkleinerten Fetzen zu Boden und die überstehende Flüssigkeit enthält einen grossen Vorrath von Spermatozoen, den man mit einem Stück feuchtem Fliesspapier zudeckt, um ihn vor Eintrocknen zu schützen.

1) Die wirklichen Hoden sind dieses nicht. Vgl. Huxley, Grundz. d. Anat. d. wirbellosen Thiere. Uebers. v. Spengel. 
Man könnte nun glauben, die aus den männlichen Geschlechtsorganen gewonnenen Spermatozoen wären zu den Versuchen ungeeignet, sie erlangten die volle Eigenthümlichkeit ihres Verhaltens erst in der Samentasche des Weibchens. Ich konnte jedoch einen solehen Unterschied nicht bemerken. Daher benutzte ich zu meinen Versuchen die von den männlichen Thieren gewonnenen Spermatozoen. Diese sind viel leichter zu erhalten als diejenigen der Samentasche.

Um Verwickelungen zu vermeiden (besonders da ich anfangs eine im Ei befindliche anziehende Substanz vermuthete, vergl. Pfeffer), nahm ich als Flüssigkeit für die Spermetozoen nur Kochsalzlösung und fand, dass jene bei einer Concentration von $0,8-0,9 \%$ am längsten am Leben bleiben.

Dass die Spermatozoen der Orthopteren in ihrer Gestalt von dem Typus der Insektenspermatozen abweichen, hat wohl zuerst Siebold ${ }^{1}$ ) (bei Heuschrecken) aufgefunden. In neuster Zeit beschäftigte sich mit diesem Gegenstand Gilson ${ }^{2}$ ). Die Spermatozoen von $\mathrm{P}$. orientalis gleichen denen der Heuschrecken. Bei schwächerer Vergrösserung betrachtet erscheinen sie den Samenfäden der Frösche nicht unähnlich.

Obgleich ich die Spermatozoen der Heuschrecken nicht beobachtet habe, so glaube ich doch aus der Aehnlichkeit im Bau der Spermatozoen selbst und derjenigen der Mikropylen schliessen zu mïssen, dass den Heuschrecken mit $P$. orientalis das eigenthïmliche Verhalten der lebenden Spermatozoen gemeinsam ist. Aber nirgends in der Literatur habe ich Angaben hieriber finden können.

Die Eigenthümlichkeit der Spermatozoen von P. orientalis besteht nun darin, dass sie sich nicht geradeaus bewegen, sondern kreisförmige Bahnen beschreiben und dass sie zweitens von Flächen angezogen werden. Letzteres sieht man, wenn man Sperma haltige Kochsalzlösung unter ein Deckglas bringt, welches sich von dem Objektträger in gewissem Abstande befindet. Die Sperma-

1) v. Si ebold, Ueber die Spermatozoiden der Locustinen. Nova Acta Vol. XXI, 1, 1845.

2) La cellule, recueil de cytologie et d'histologie génërale, publié par Carnoy. T. I, 1. (Etude comparée de la spermatogenèse chez les arthropodes par Gilson). 
Ueber Gesetzmässigkeit in der Ortsveränderung der Spermatozoen etc. 361

tozoen sammeln sich in diesem Falle nur oben am Deckglase und unten auf dem Objektträger an; dazwischen fehlen sie. Oder wenn man eine Kugel in Spermaflüssigkeit legt, bezw. dieselbe damit anfüllt, so verlassen die Spermatozoen niemals die Fläche (Aussenbezw. Innenfläche) jener.

Diese Anziehung, Anlockung der Spermatozoen lässt sich mit andern bekannten Vorgängen vergleichen. Wie die Spermatozoen der Farnkräuter durch den Reiz, den Apfessäure auf sie ausübt, angezogen werden und sich nicht von dem Ort entfernen, an dem sich dieselbe befindet; wie eine ähnliche Wirkung das Licht bei niedern Organismen hervorruft, so seheint hier die Unterlage, die Fläche zu wirken, auf der sich die Spermatozoen von $P$. orientalis bewegen.

Es war nöthig, das Wesentlichste über die Flächenanziehung vorauszuschicken, damit die Erscheinungen der Kreisbewegung verständlich werden.

Die auf Flächen befindlichen Spermatozoen nun beschreiben bei ihrer Bewegung beständig Kreislinien. Natürlich sind dieselben nicht annähernd genau, sondern weichen hier nach aussen, dort nach innen von der regelmässigen Bahn ab, wozu sie schon durch im Wege liegende Hindernisse oft gezwungen werden. Wenn auch, wie es bisweilen vorkommt, ein Spermatozoon eine kleine Strecke geradeaus gegangen ist, und man glaubt, nun werde es diese Richtung beibehalten, so wird es doch stets wie mit Gewalt in die Kreisbahn zurückgezogen.

Abgesehen davon, dass das Spermatozoon grössere oder kleinere Unregelmässigkeiten macht, hält es auch bei jedem folgenden Umlauf nicht an der einmal angenommenen Bahn fest, sondern verschiebt jedesmal etwas die kreisförmige Linie. Hierin besteht aber keine Gesetzmässigkeit, indem jene etwa nach einer bestimmten Richtung wandert, sondern es ist ein unregelmässiges Hinund Herricken.

Wie ich eben angegeben habe, bewegen sich die Spermatozoen oft eine Strecke in gerader Richtung, gehen aber doch früher oder später in die kreisförmige iiber. Vielleicht lässt sich diese Erscheinung dureh die Annahme erklären, dass die Flüssigkeitsschicht, welche die Fläche berührt, eine andere Beschaffenheit besitzt als die iibrigen Schichten, und dass jene die Spermatozoen zur Kreisbewegung veranlasst. Auf jener Strecke würde dann das 
Spermatozoon aus der bezeichneten Fliissigkeitsschicht herausgerathen sein. Für diese Annahme spricht auch das Verbalten der Spermatozoen während derjenigen Zeit, wo sie die Fläche noch nicht erreicht baben, wo sie so zu sagen noch frei in der Flüssigkeit schweben und keine Stütze gefunden haben 1). Besonders aber möchte ich folgenden Versuch hier erwähnen. Versetzt man die Kochsalzlösung mit Gummi arabicum, so dass man eine schleimige Flüssigkeit erhält, vermischt diese mit Sperma und bringt sie zwischen Deckglas and Objektträger (welche sich in kleinem Abstande voneinander befinden), so sind die Spermatozoen verhindert, sich zur Fläche zu begeben. In diesem Falle schwimmen sie unregelmässig und planlos umher; von Kreisbewegungen ist nichts zu sehen. Derselbe Erfolg wird erzielt, wenn man den Objektträger mit jener schleimigen Masse bestreicht und dann etwas Flüssigkeit mit Spermatozoen anf die so behandelte Fläche bringt.

Die Richtung der Kreisbewegung scheint auf den ersten Blick sehr merkwürdig zu sein. Wenn man nämlich unter dem Deckglase, das sich wieder vom Objektträger in gewissem Abstande befindet, einen Tropfen Spermaflüssigkeit bringt, so bemerkt man, wie sich ron den Spermatozoen die einen in entgegengesetzter Richtung bewegen als die andern. Die Annahme liegt sehr nahe, dass man es hier mit zwei verschiedenen Arten von Spermatozoen zu thun hat, deren sonstige unterscheidenden Merkmale sich leicht der Beobachtung entziehen. Doch, wie sich bei genanem Zusehen herausstellt, hat man nicht auf die Einstellungsebene des Mikroskopes geachtet, denn die am Deckglas befindlichen Spermatozoen bewegen sich in entgegengesetzter Richtung als diejenigen auf dem Objektträger. Diese Erscheinung lässt sich leicht erklären. Man erweitert den Abstand zwischen beiden Glasfäehen durch Zwischenlegen von Glasstiickchen und dergl., um die Spermatozoen am Deckglase und auf dem Objektträger zu unterscheiden. Diese bewegen sich für den Beobachter links herum d. h. entgegengesetzt dem Zeiger der Uhr, jene rechts, also mit dem Zeiger derselben²).

1) Vgl, unten.

2) In meiner Mittheilung (dieses Archiv 1885) habe ich einen Irrthum begangen, auf welchen mich Herr Professor Grenacher gütigst aufmerksam gemacht hat. Ich habe nämlich dort gesagt, dass die Richtung in der kreisförmigen Bewegung durch das Mikroskop umgekehrt würde, dass aus einer rechtsläufigen Bewegung unter dem Mikroskop eine (scheinbar) linksläufige 
Ueber Gesetzmässigkeit in der Ortsveränderung der Spermatozoen etc. 365

Man hat es nun aber nicht mit zweierlei Spermatozoen zu thun, sondern nur mit einer Art, denn die Bewegungsrichtung ist in beiden Fällen dieselbe. Wir haben nämlich bei ihrer Beurtheilung einen Fehler begangen. Wir beurtheilten beidemal ganz unbewusst die Richtung der Bewegung nach der Richtung der Schwerkraft (bezw. der Sehachse); diese aber verschwindet, wie die Ansammlang der Spermatozoen am Deckglase zeigt, gegenüber der Flächenanziehung. Die Bewegung hat nun zwar keine Beziehung zur Erdachse, wohl aber eine solche zur anziehenden Fläche. Wenn wir von dieser aus die Bewegungsrichtung beurtheilen, werden wir zu einem andern Resultat gelangen.

Die benetzte Fläche des Deckglases - an der die Spermatozoen enthalten sind - sieht nach unten, die des Objektträgers nach oben. Der Beobachter nimmt also in beiden Fällen einen entgegengesetzten Standpunkt ein, und nur für ihn, nicht für die benetzte Fläche des Glases ist die Bewegung eine verschiedene.

Bezeichnet man mit $\boldsymbol{A}$ das Auge des Beobachters, welcher herab auf das Deckglas und den Objektträger sieht; mit $f$ die Flüssigkeit, welche sich zwischen den beiden Gläsern befindet; mit $a_{l}$ die der Luft, mit $a_{f}$ die der Flüssigkeit zugekehrte Seite des Deckglases ; mit $\alpha_{l}$ und $\alpha_{f}$ das Entsprechende am Objektträger; mit $s$ die Flüssigkeitssehicht, welche am Deskglase und mit $\sigma$ diejenige, welche auf dem Objektträger die Spermatozoen enthält, dann lautet die Reihenfolge von $A$ aus: 1) $a_{l}, a_{f}, s, f$; 2) $f, \sigma$, $\alpha_{f}, \alpha_{l}$. Da sich $\alpha_{l}$ und $\alpha_{l}, a_{f}$ und $\alpha_{f}, s$ und $\sigma$ entsprechen, so ist die Reihenfolge für $A$ im ersten Falle eine entgegengesetzte wie im zweiten. Wie hierdurch die Richtung der Bewegung in dem einen Falle eine entgegengesetzte sein muss als im andern, kann man sich durch eine kleine Ueberlegung klar machen. Merkt man sich bei einer auf dem Tische liegenden Taschenuhr die Bewegungsrichtung der Zeiger und legt dann die Uhr umgekehrt auf die Tischplatte, so dass das Glas diese berührt, so wird man, wenn man jetzt den Weg der Zeiger im Geiste verfolgt, finden, dass nun die Bewegungsrichtung jener für den Beobachter eine entgegengesetzte geworden ist.

Ueber die Richtung in der Bewegung der Spermatozoen gel-

werde. Diese falsche Vorstellung scheint weit verbreitet zu sein. Sie berührt aber nicht weiter den Inhalt meiner Ausführungen, 
ten daher folgende Angaben. Sehen wir auf eine Fläche, auf der sich Spermatozoen bewegen, wie man das Zifferblatt einer Uhr betrachtet, so bewegen sich die Spermatozoen stets umgekehrt wie die Zeiger der Uhr. Die Umlaufsrichtung der Spermatozoen in ihrer Kreisbaln ist unter jener Voraussetzung immer eine linksläufige.

Diese Auseinandersetzungen über rechts - und linksläufige Kreisbewegung der Spermatozoen geiten auch für krumme Fächen.

Ich habe oben angedeutet, dass die Spermatozoen nicht nur von ebenen, sondern auch von krummen Flächen angezogen werden. Wenn man nun die Spermatozoen sich auf der Oberfläche einer Kugel bewegen lässt, so ist für das beobachtende Auge die Richtung eine linkslänfige; eine rechtsläufige dagegen, wenn man die Kugel mit Spermaflüssigkeit füllt, so dass die Spermatozoen sich auf der Innenfläche bewegen. Die Erklärung hierfür lautet ebenso wie vorher. Es ist leicht verständlich, dass, wenn das Auge seinen Standpunkt nicht verändert, sich von den Spermatozoen nur ein kleiner Bezirk übersehen lässt. Ferner müssen die Bahnen um so mehr elliptisch erscheinen, je weiter sie sich von der Verbindungslinie des Auges mit dem Kugelmittelpunkt entfernen ${ }^{1}$ ).

Es wurde oben der Anziehnng der Spermatozoen durch Flächen nur flüchtig Erwähnung gethan, um die Erörterungen iiber die kreisförmigen Bewegungen zu verstehen. Es ist daher jetzt nöthig, auf jenen Punkt näher einzugehen.

Bringt man wieder zwischen Deckglas und Objektträger, welche sich im Abstande von einander befinden, Spermaflüssigkeit und betrachtet nach wenigen Minuten das Präparat, dann

1) Ueber Kreisbewegung von Spermatozoen habe ich eine kurze Notiz gefunden bei Eimer, Unters. über d. Bau und d. Bewegung der Samenfäden (Verh. d. physik.-med. Gesellsch. zu Würzburg 1874). Eimer erwähnt hier (S. 125), dass sich die Spermatozoen des Menschen, falls ihre Kräfte erlahmen, nicht in gerader linie, sondern in Kreisen bewegen. Um eine derartige krankhafte Erscheinung kann es sich bei den Spermatozoen von Periplaneta orientalis auf keinen Fall handeln, denn ich habe dieselben nicht von einigen wenigen Thieren, sondern von unzähligen beobachtet. Niemals sah ich, dass diejenigen Spermatozoen, welche Kreise beschrieben, im Absterben begriffen waren. Im Gegentheil, bei den lebensfähigsten zeigte sich am schönsten die Eirscheinung. 
Ueber Gesetzmässigkeit in der Ortsveränderung der Spermatozoen etc. 365

findet man nur unten, da wo die Flüssigkeit den Objektträger und oben, wo sie das Deckglas berïhrt, Spermatozoen, hier wie dort die Kreisbewegung zeigend. Dazwischen enthält die Flüssigkeit nur todte oder absterbende Spermatozoen. Diejenige Flüssigkeitsschicht, welche den Objectträger beriuhrt $\left.(\sigma)^{1}\right)$, lässt sich an den niedergesunkenen Fetzen, welche von den männlichen Geschlechtsorganen ${ }^{2}$ ) herstammen, erkennen; die das Deckglas berührende $(s)$ an kleinen Kügelchen, die sich, vielleicht weil sie Fetttröpfchen sind, ganz oben an der Innenseite des Deckglases befinden. Wie es natuirlich ist, sind die Spermatozoen nicht augenblicklich in beiden Schichten ( $\sigma$ und $s$ ) vorhanden, sobald man sie zwischen Deckglas und Objektträger gebracht hat. Man braucht ihnen jedoch nur wenige Secunden zur Orientirung zu lassen. Es lässt sich dabei beobachten, wie die Spermatozoen mit Unrube und Unbehagen, wenn ein solcher Ausdruck erlaubt ist, umberschwimmen, um eine Fläche zu erlangen. Sie verändern dabei fortwährend die mit dem Mikroskop eingestellte Ebene, um in die Tiefe zu steigen oder emporzutauchen. Erst nachdem sie an der Fläche angelangt sind, nehmen sie eine ruhige, regelmässige Kreisbewegung an. Besonders an der obern Schicht $(s)$ lassen sich diese Vorgänge gut beobachten.

In den Erscheinungen der Flächenwirkung und der kreisförmigen Bewegung wird nichts geändert, falls zwischen Deckglas und Objectträger nur ein kapillarer Raum gelassen wird, indem man das Deckglas unmittelbar auf den Objectträger legt und Spermaflüssigkeit dazwischen laufen lässt. Anfangs sehen wir die Spermatozoen durch einander nach rechts oder nach links kreisen. Jedoch bei Anwendung starker Vergrösserungen und genauer Einstellung kann leicht festgestellt werden, dass auch hier zwei Schichten vorhanden sind, in denen sich Spermatozoen bewegen, eine obere mit rechtsläufigen und eine untere mit linksläufigen.

Man könnte glauben, die zwischen Deckglas und Objectträger gebrachten Spermatozoen sinken zu letzterem nieder und nur diejenigen, welche in dem Durcheinander der Spermaflüssigkeit mit dem Deckglas in Berührung kommen, werden von diesem

1) Vgl. oben.

2) Vgl. oben die Gewinnung der Spermatozoen. 
festgehalten. Diese Ansicht wird durch das oben über das Empor- und Hinabsteigen Gesagte widerlegt; es beweist dasselbe, dass die Spermatozoen sich anfangs regellos umberbewegen und erst dann dem Objectträger bezw. Deckglas zusteuern, wenn sie im Bereich der Anziehung derselben sind.

Diejenigen Spermatozoen, welche einmal an einer Fläche angelangt sind, verlassen diese nicht mehr, sondern führen auf ibr ihre Bewegungen aus. Auf einer Ebene, könnte man einwenden, haben sie zum Verłassen der Fläche vielleicht gerade keine Veranlassung (allerdings habe ich während meiner mehrmonatlichen Beobachtungen immer ein und dieselbe Wahrnehmung gemacht). Um solches Bedenken zu beseitigen, habe ich untersucht, wie sich die Spermatozoen zu einer gekrümmten Fläche z. B. zu einer Kugelfäche verhalten. In dem Falle, dass sie nicht von Flächen angezogen würden, nicht an ihre Unterlage gebunden wären, müsste ein Spermatozoon, dass sich gerade auf einer Kugelfläche befindet, den Krïmmungen derselben nicht nothwendig folgen, sondern es würde sehr bald die Oberfläche verlassen; es würde seine Bewegungsebene nicht beständig mit der Tangentialebene ändern. In Wirklichkeit aber kann ein Spermatozoon, welches einmal auf der Kugelfäche ist, diese niemals wieder verlassen; es muss darauf bleiben, gleich wie von einem Magneten f'estgehalten. Um dieses ${ }^{1}$ ) zu zeigen, wird auf einem Objektträger aus vier Lamellen von Wachs ein kleiner Kasten bergestellt, den man dann mit Kochsalzlösung fïllt. In diesen legt man eine kleine Kugel, wie man sie leicht aus einem Glasrohr ausbläst; jedoch muss sie ein kleines Loch haben, damit Flüssigkeit eindringt, welche die störende Brechung beseitigt. Darauf wird etwas Sperma in die Kochsalzlösung des Wachskästchens geschütttet. Indem man nun sein Augenmerk auf die Oberfläche der Kugel richten will, fällt es nicht schwer, dieselbe wahrzunehmen, denn sie ist durch die niedergesunkenen Körnchen u. s. w. der Spermamasse gekennzeichnet. Die Oberfläche lässt sich aber auch dadureh kenntlich machen, dass man mit einem Stïckchen Wachs leise über sie hinfährt; in Folge dessen bleiben sehr feine Wachsstitckchen hängen ${ }^{2}$ ).

1) Dieses gilt natürlich auch für die früheren Beobachtungen über das Verhalten der Spermatozoen auf Kugelflächen.

2) Auch bei einer Ebene lässt sich ein derartiges Mittel in Anwendung bringen, nur ist es dort leichter zu entbehren. 
Auf diese oder die erwähnten Körnchen stellt man das Mikroskop ein, um die Oberfläche der Kugel zu erreichen.

Da die Spermatozoen die Oberfläche der Kugel nie verlassen und somit auf ihrer Kreisbahn die Ebene, in der sie sich bewegen, beständig ändern, so muss man mit dieser Veränderung gleichen Schritt haltend die Einstellung des Mikroskops fortwährend wechseln. Nehme ich an, ein Spermatozoon befindet sich auf dem für den Beobachter am höchsten gelegenen Punkt seiner Kreisbahn ${ }^{1}$, so muss jener, will er das Spermatozoon immer scharf in Auge behalten, den Tubus senken bis zu dem niedrigsten Punkte; von hier ab wird er bis zum Ausgangspunkte gehoben.

In Versuchen, bei denen sich die Spermatozoen auf der Innenfläche der Kugel bewegen sollen, bringt man die Spermamasse in die Kugel hinein; sonst aber bleiben die Verhältnisse ziemlich die gleichen.

Wie eine Fläche wirkt auch die Luft. Um dieses zu veranschaulichen, wird ein Tropfen mit Spermatozoen an dem Deckglase hängend in der feuchten Kammer beobachtet. Die an der Fläche des Deckglases befindlichen Spermatozoen bewegen sich dann rechts herum, diejenigen auf der Kuppe des Tropfens links herum. Die Luft hat hier also dieselbe Wirkung, als wenn ein concaves Stück Glas den Tropfen umschliessen würde. Aendert man den Verzuch dahin $a b$, dass man einen Tropfen a u $f$ ein Stiick Glas bringt und ihn durch passende Mittel nicht anseinander fliessen lässt, so ist die Richtung der Bewegung auf der Kuppe eine rechts-, auf der Glasfläche eine linksläufige.

Das Haften an Flächen scheint nur lebenden Spermatozoen zuzukommen. Dieses ist auch eine nothwendige Voraussetzung, falls meine am Anfange ausgesprochene Ansicht bestehen soll, dass die Wirkung von Flächen auf die Spermatozoen von Periplaneta orientalis zu vergleichen ist mit derjenigen von Licht auf niedre Organismen oder von Aepfelsäure auf die Samenfäden der Farnkräuter.

Ich brachte nämlich in die Höhlung eines ausgeschliffenen Objektträgers Kochsalzlösung mit einer reichlichen Menge von Spermatozoen, wartete bis sich viele von denselben auf der Ober-

1) $\mathrm{Da}$ sich die Kreisbahn auf einer Kugeloberfläche befindet, liegen für den Beobachter ihre Punkte verschieden hoch. 
fläche angesammelt hatten und zog darauf den Tubus in die Höhe. Dann deckte ich über die Vertiefung des Objektträgers ein kleines Trichterchen, in dessen Hals mit Osminmsäure ${ }^{1}$ ) getränkte Watte steckte. Die Spermatozoen starben von der Säure rasch. Ich liess aber das Ganze noch etwa 20 Minuten stehen und sah nun, indem ich den Tubus wieder einstellte, nach, ob sich die Spermatozoen, welehe sich vorher in grosser Zahl auf der Oberfläche der Flüssigkeit umhertrieben, noch dort befänden. In vielen Fällen war kaum ein Spermatozoon zu finden, in andern bemerkte ich eine grössere Anzahl von ibnen. Dann sehienen sie aber von Tröpfchen and Körnchen der Samenmasse festgehalten $\mathrm{zu}$ werden.

Schliesslich könnte man betreffs meiner Mittheilungen über das Verhalten der Spermatozoen der Schabe noch einen Einwand als nicht widerlegt betrachten. Man könnte meinen, wenn auch allerdings die Richtung der Bewegung an der obern und untern Anziehungsfläche nur scheinbar eine entgegengesetzte ist, so wäre es dennoch nicht unmöglich, dass es zweierlei Arten von Spermatozoen giebt, von welchen die einen die Eigenschaft baben emporzutauchen, die andern in die Tiefe zu wandern. In Folge dessen würden am Deckglas wie am Objektträger Spermatozoen gefunden. Ein derartiger Einwand lässt sich in folgender Weise beseitigen. Ein kleines Glasröhrchen wird mit Kochsalzlösung angefüllt, Sperma hinzugefügt und der Inhalt umgeschüttelt. Nachdem es eine Weile ruhig gestanden, müsste sich jetzt gemäss jener Annahme die eine Art der Spermatozoen nur oben, die zweite nur unten befinden. Man nimmt deshalb etwas von der Fliussigkeit des Randes mittelst einer Capillare heraus. In dieser Probe diurfen nur Spermatozoen der ersten Art enthalten sein. Der Prüfung halber wird sie zwischen Deckglas und Objektträger gebracht. Doch auch jetzt hat man das bekannte Bild: oben und unten Spermatozoen.

In wiefern nun die Eigenschaften der Spermatozoen von Periplaneta orientalis von Nutzen sind, wenn es darauf ankommt, dass jene in die Mikropylen hineintreffen, das kann erst klar werden, wenn (im folgenden Abschnitt) die Oberfläche des Eies beschrieben

1) Chloroform wurde wegen dessen Schädlichkeit für die Linsen des Mikroskopes vermieden. 
sein wird. Hier aber mögen sich an die Ausführungen über die Bewegung der Spermatozoen der Schabe noch einige Bemerkungen anschliessen ïber denselben Gegenstand bei Dreyssena polymorpha, jener in nenerer Zeit eingewanderten Muschel.

Die Spermatozoen von Dreyssena zeigen in ihrem Verhalten eine gewisse Aehnlichkeit mit denen von Periplaneta. Wenn der aus dem Fusse herausgenommene Samen mit Wasser verdünnt wird, liegen die Spermatozoen anfangs rubig da ${ }^{1}$ ), dann fangen einige an mit dem Kopfende hin- und herzuschlagen. Es beginnt hierauf eine langsame Bewegung des Spermatozoons, welche an die kriechende Bewegung der Infusorien auf dem Objektträger erinnert; allmählich wird die Bewegung schneller und schneller. Dieselbe ist aber nicht geradeaus gerichtet, sondern geschieht in engen Kreisbahnen, wobei jedoch der Gesammteindruck ganz anders ist wie bei Periplaneta. Denn während dort die Bewegung ruhig und gleichmässig von Statten geht, ist sie bei Dreyssena eine hüpfende, höchst unruhige. Sie gleicht ganz und gar derjenigen von Gyrinus, dem kleinen Käfer, weleher sich auf der Oberfläche der Gräben und Pfitzen blitzschnell in Kreisen bewegt.

Wenn nun immer mehr Spermatozoen erwachen und sich in der beschriebenen Weise umhertummeln und schliesslich unzählige förmlich umherwirbeln, so gewährt dies einen höchst eigenthümlichen Anblick. Oft halten sie anch in ihrer Bewegung an und liegen eine Zeitlang still ${ }^{2}$ ).

Da ich die eigentliche Zeit der Fortpflanzung (Spätsommer) verpasste, so konnte ich eingehendere Untersuchungen nicht anstellen. Doch glaube ich nach den gemachten Beobachtungen, dass auch hier wie bei Periplaneta eine Anziebung der Spermatozoen durch Flächen besteht.

\section{D as Ei.}

An dem bohnenförmig gebogenen Ei interessirt uns nur die Oberfläche, und an dieser die Mikropylen. Diese bedürfen keiner eingehenden Behandlung, demn sie unterseheiden sich, von gering-

1) Vgl. G. Platner, die Struktur und Bewegung der Samenfäden bei den einheimischen Lungenschnecken. Göttingen 1885, S. 11.

2) dass. S. 13. 
fügigen Einzelheiten abgesehen, kaum von denen anderer Orthopteren. Es genügt, wenn ich auf die ausfithrlichen Beschreibungen und auf die Abbildungen der Heuschreckeneier in der betreffenden Arbeit Leuckart's ${ }^{1}$ ) verweise.

Bei Periplaneta orientalis sind die Mikropylen (Fig. 4) in grosser Anzahl vorhanden. Kady i ${ }^{2}$ ) giebt $80-100$ an. Sie liegen auf dem Riucken der convexen Seite des Eies einzeln oder in Gruppen, dem vorderen ${ }^{3}$ ) Pole genähert. Bei ihrer trichterförmigen Gestalt haben sie alle dieselbe Richtung; sie sind nämlich mit der engen Oeffnung dem vordern, mit der weiten dem hintern Pole (Fig. $4 \mathrm{~h} \mathrm{p}$ ) zugekehrt. Die weite Oeffnung ist der Eingang, liegt also in der Oberfläche der Eischale, die enge ist die Ausmündung und befindet sich im Innern des Eies. Der Trichter lässt sich nicht mit einem Kegel vergleichen, welcher senkrecht zur Eibaut steht und dessen Basis ein Kreis ist, sondern mit einem solchen, dessen Grundfläche elliptisch ist und dessen Axe mit der Oberfläche des Eies einen spitzen Winkel bildet. Die elliptische Basis des Trichters oder vielmehr der elliptisehe Rand des Trichtereinganges folgt mit seiner grossen Axe der Längsricbtung des Eies. Nun ist aber der Rand in Wirklichkeit keine regelmässige oder annähernd regelmässige Ellipse, sondern er ist an dem nach hinten (Richtung hp) weisenden Fndpunkte seiner grossen Axe zu einem Zipfel ausgezogen. Dieser liegt etwas niedriger als der entgegengesetzte Theil des Trichterrandes. Dadurch findet dort ein all-

1) Leuckart, Ueber die Mikropyle und den feinern Bau der Schalenhaut bei den Insekteneiern. Müller's Arch. 1855 (vgl. besonders die Ahbildung Taf. X, 17). - Von Blattideneiern ist nur bei B. germanica eine Beschreibung und Abbildung vorhanden. Hier seheinen aber die Verhältnisse ganz anders zu liegen als bei Periplaneta (Blatta) orientalis, denn L. giebt nur eine Mikropyle an. In Uebereinstimmung mit dieser Abweichung besitzen die Spermatozoen von B. germanica den gewöhnlichen Typus der Insektenspermatozoen. Sie sind fadenförmig und von sehr bedeutender Länge, während die Spermatozoen von P. orientalis sich mit den Froschspermatozoen vergleichen lassen.

2) H. Kadyi, Beitrag zur Kenntniss der Vorgänge beim Eierlegen der Blatta orientalis, zool. Anz. II. Jahrg. (1879), No. 44. Vorl. Mittheil. (Eine ausführliche Arbeit babe ich nicht finden können.)

3) Mit vorn wird im Folgenden alles das bezeichnet, was dem Kopfe des Thieres; mit hinten, was dem Afterende; mit oben, was dem Rücken, und mit unten, was dem Bauche zugekehrt ist. 
Ueber Gesetzmässigkeit in der Ortsveränderung der Spermatozoen etc. 371

mählicher Uebergang von der Eioberfläche zum Innern des Trichters statt, währead hier gleichsam ein Fangschirm vorhanden ist.

Wie Fig. 4 zeigt, kommen Abweichungen von der eben beschriebenen Grundform vor. Bisweilen ist der Rand der Eingangsöffnung unregelmässig oder der Trichter hat sich auf die Seite geneigt.

Die Gestait der Mikropylen erscheint für das Hineingelangen der Spermatozoen in dieselbe sofort von grossem Werthe, wenn man sich die Eigenschaften jener vergegenwärtigt.

Wenn die Spermatozoen aus der Mündung des Samenganges gegen die Eioberfläehe, auf welcher die Mikropylen sich befinden, berausgepresst werden ${ }^{1}$ ), so werden die Spermatozoen von der Oberfläche des Eies festgehalten, das heisst sie bewegen sich auf ihr, können sie aber nicht verlassen. Da die Mikropylen die beschriebene Eingangsöffnung besitzen, welche wie zum Fangen eingerichtet ist, und da man ron der Oberfläche allmählich in sie hineingelangt, so würde die eine Eigenthümlichkeit schon genügen, um die Spermatozoen in die Mikropylen hineinzuleiten. Doch könnte es leicht geschehen, dass das Spermatozoon bei gerader Richtung seiner Bewegung an dem Mikropyleneingang voribergeht, ihn so verfehlt und weiter eilt. Allerdings wïrde es nach einer kleinen Strecke wieder auf Mikropylen stossen. Aber die Sicherheit des Hineintreffens wird erhöht durch die zweite Eigenschaft der Bewegung, durch die kreisförmige Richtung. Durch diese werden die Spermatozoen veranlasst, im grossen ganzen in demselben Be. zirk der Eioberfäche zu bleiben; sie kommen innerhalb desselben zu den einmal beriihrten Punkten oder in die Nähe derselben zurück. Trafen sie beim ersten Mal nicht in die Mikropylenöffnung, so kann es beim zweiten, dritten oder einem folgenden geschehen, weil die Kreisbahn immer etwas versehoben wird, hin- und herrückt.

An frischen, unversehrten Eiern, wie man sie aus dem Thiere herausnimmt ${ }^{2}$, lassen sich diese Vorgänge nicht prüfen, denn das

1) Vgl. später.

2) Will man aus dem Eierstock einer beliebigen weiblichen Schabe die Eier herausnehmen, welche durch ihre Grösse den Eindruck der Reife hervorrufen, so gelingt dieses nicht immer. Oft zerreisst das $\mathrm{Ei}$ und der Inhalt fliesst heraus. Solche Eier sind noch nicht reif. Ob aber reife Eier schon vorbanden sind, kann man dem Thiere äusserlich ansehen. Wenn dieses näm- 
Ei ist ganz undurchsichtig. Ich drüekte deshalb den Inhalt desselben heraus und wollte jetzt beobachten, wie sich die Spermatozoen zur Eihaut verhalten. Es blieben jedoch noch zu viel Dotterstiicke u. s. w. auf der Innenseite der Haut haften, so dass ich, da jene durch letztere deutlich hindurchscheinen, das schnell bewegliche Spermatozoon leicht aus den Augen verlor. Darauf machte ich den Versuch, ob sich die Eihaut bei gehärteten Eiern besser ablösen lässt. Dieses glückte, indem ich die Eier kürzere Zeit in Osmiumsäure legte und sie dann in Alkohol brachte, wo sie einige Tage blieben. Ein tagelanges Liegen in Platinchlorid wirkte noch besser wie die Behandlung mit Osmiumsäure. Bei den mit der einen oder der andern Substanz gehärteten Eiern hebt sich die Eihaut von dem Inhalt ab; es entsteht zwischen beiden ein Zwischenraum, was bei Eiern, auf welche Sublimat oder allein Alkohol einwirkt, nicht der Fall ist. Wird dann von den Eiern die Eihaut stiuckweise entfernt, so haftet nur noch hin und wieder ein Körnchen an ihr und die Beobachtung wird jetzt nicht gestört. Natürlich müssen die Stücke der Eihaut gehörig ausgewässert werden, ehe man mit ihnen Versuche anstellt.

Dieselben entsprachen der obigen Ansicht darüber, wie die Spermatozoen in die Mikropylen hineingeleitet werden. Die Spermatozoen beschrieben auf der Haut ihre Kreise und befanden sich oft gefangen in den Mikropyleneingängen; dabei suchten sie sich mit aller Gewalt durch das röhrenförmige Ende hindurchzubohren welches durch die Behandlung des Eies verstopft sein musste.

Hierbei kann man sich nicht verhehlen, dass dieser Versuch noch keine Bestätigung jener Ansicht ist. Denn mit Recht wird man einwenden, dass möglicherweise bei dem frischen $\mathrm{Ei}$ die Verhältnisse etwas anders liegen, und dass bier Dinge zur Geltung kommen, die dort, beim gehärteten $\mathrm{Ei}$, unbeachtet geblieben sind.

Bei einem Vergleich zwischen der Oberfläche eines frischen und eines gehärteten Eies kann ich nur einen unterscheidenden

lich an seinem hinteren Ende die weissen Häute entfaltet, welche dazu dienen, den spätern Eiersack festzuhalten, dann weiss man, dass sich das Thier zum Eierlegen anschickt, dass es mithin reife Eier besitzt. Bei einer solchen Schabe lassen sich die Eier leicht aus den Eierstocksröhren herausschälen; gewöhnlich nimmt schon je ein Ei die Eileiter ein (vgl. Fig. 5a), aus welchen man sie ohne jede Mühe befreien kann. 
Ueber Gesetzmässigkeit in der Ortsveränderung der Spermatozoen etc. 373

Punkt herausfinden. Dieser ist aber derartig, dass er unsere Beachtung verdient. Es handelt sich nämlich um die "schleimige" Oberfläche des frischen Eies.

Ich habe oben gesagt, die kreisförmige Bewegung der Spermatozoen wird aufgehoben, wenn die Flüssigkeit, in der sie sich befinden, schleimiger Natur ist. Ueberall in der Literatur findet sich aber die Angabe, dass die ausgebildeten Insekteneier mit einem schleimigen Ueberzuge versehen sind. Ueber diesen habe ich bei Fliegeneiern etwas in Erfahrung gebracht.

Leuckart ${ }^{1}$ ) nennt den Ueberzug der Insekteneier Eiweissschicht. Ich glaube aber, dass es sich hier weder um Eiweiss, noch um Schleim handelt. Beim Fliegenei ist nämlich der Pol, an welchem sich die Mikropyle befindet, mit einem hohen $\mathrm{Wulst}^{2}$ ) versehen, an welchen sich der Ueberzug der Eioberfläehe anschliesst $\left.^{3}\right)$. Dieser Wulst ist zusammenziehbar $\left.{ }^{4}\right)$. Bei Zusatz von starkem Alkohol, von Säuren und anderen Substanzen verschwindet er allmählich; spiilt man dann aber das Ei mit Wasser ab, so kommt er wieder zum Vorschein und hat nach einiger Zeit seine alte Höhe erreicht. Dieses lässt sich an ein und demselben Ei viele Male wiederholen.

Ein solches Verhalten würde nun mit der Zusammensetzung des Zapfens aus Eiweiss- oder Schleimmasse unvereinbar sein; besonders wenn ich noch hinzufüge, dass ich mit den stärksten

1) a. a. 0 .

2) Vgl. Lenckart a. a. 0. - Ferner Leuckart, Die Fortpfl. und Entw. d. Pupiparen. Abhand. d. naturf. Gesellsch. zu Halle. Bd. IV, 1858. Leydig, Der Eierstock u. d. Samentasche d. Insekten. Nova Acta, Bd. XXXIII, 1866. - Meissner, Beobacht. über d. Eindringen d. Samenelemente in d. Dotter. II. Zeitschr. f. wiss. Zool. 1855.

3) Der Wulst ist nur scheinbar eine Verdickung des Ueberzuges, denn in Wirklichkeit hat letzterer in der Umgebung der Mikropyle eine schüsselförmige Vertiefung, in welcher ein Zapfen steckt, der mit der Mikropyle in Verbindung steht und den Ueberzug bedeutend überragt. Letzteres erweckt den Schein, als ob in der Gegend der Mikropyle der Ueberzug wulstartig verdickt ist. In diesem Zapfen oder Wulst befinden sich, wie es scheint, Röhren (dasselbe sagt Leuckart, die Fortpflanz. und Entw. d. Pupiparen, S. 162, Taf. II, Fig. 1), in denen nach stattgefundener Befruchtung die Spermatozoen stecken.

4) Was für das Hineingelangen der Spermatozoen in die Mikropyle wahrscheinlich grossen Werth hat. 
Säuren (fast concentrirter Salpetersäure) den Mechanismus nicht zerstören konnte.

Die gleichen Erscheinungen nahm ich an der Gallerthïlle der Froscheier wahr. Eine Menge derselben, welche seit Anfang April bis Ende December in Alkohol lagen und deren Hülle gänzlich zusammengeschrumpft war, wässerte ich aus; nachdem sie nur wenige Minuten im Wasser gelegen hatten, war die Hülle sichtlich gequollen. Die Quellung nahm zu, bis sie den Umfang wie bei frisehen Eiern erreicht hatte. Darauf schiutte ich die gequollenen Eier wieder in Alkohol und liess sich den Vorgang wiederholen.

Wie der Wulst des Fliegeneies ist auch die Hülle der Froscheier in gewisser Hinsicht unverwüstlich, denn die zuletzt genannten Eier liess ich viele Stunden in Salpetersäure liegen, ohne dass die Huille dadurch zerstört wurde. Dagegen wirkte in beiden Fällen unterchlorigsaures Natrium (Eau de Javelle) augenblicklich lösend.

Der Ueberzug des Fliegeneies besteht sicherlich aus denselben Stoffen wie der an ihm vorhandene Wulst; danach wäre jener durchaus nicht so flüssig (schleimig), wie man anzunehmen scheint, sondern müsste eher fest als flüssig genannt werden. Ferner aber ist man wohl gezwungen anzunehmen, dass die Eier beider Insekten, der Fliege und der Schabe, mit ein und derselben Substanz überzogen sind. Der Einwand also, die Spermatozoen könnten sich bei $P$. orientalis auf der Eioberfläche in der bekannten Weise nicht bewegen wegen des schleimigen Ueberzuges, würde aus diesen Gründen hinfällig ${ }^{1}$ ).

1) Ich möchte an dieser Stelle auf Gebilde an den Eiern anderer Thiere hinweisen, welche eine ähnliche Bedeutung haben mögen, wie der Wulst des Fliegeneies. Kupfer und Benecke (der Vorgang d. Befruchtung am Ei der Neunaugen, 1878) geben an, dass derjenige Pol, in welchen die Spermatozoen eindringen, von einer hohen durchsichtigen Kuppe bedeckt ist. Ferner erwähnt Keber in seinen bekannten Untersuchungen, dass schleimige Masse aus der Mikropyle austrete. Auch das Keber'schen Körperchen wird vielleicht in besagtem Sinne seine Erledigung finden. 
Ueber Gesetzmässigkeit in der Ortsveränderung der Spermatozoen etc. 375

Der Ort der Befruchtung und die hierbei in Betracht kommenden weiblichen Geschlechtstheile.

Jetzt nachdem dasjenige, was ich über den vorliegenden Gegenstand habe in Erfahrung bringen können, gesagt ist, wäre diese Arbeit abzuschliessen. Bevor dieses jedoch geschieht, möchte ich meine Angaben ïber das Hineinfinden der Spermatozoen in die Mikropyle gewissermaassen einer Probe unterziehen. Sollen sie nämlich von Bestand sein, so darf ihnen bei den örtlichen Verhältnissen, die bei der Befruchtung in Betracht kommen, nichts widersprechen, sondern es muss sich eine gewisse gegenseitige Anpassung herausstellen.

Dieses fïhrt mich auf die Schilderung der weiblichen Geschlechtstheile ${ }^{1}$ ) im Bereich der Ausmïndung des Samenganges, wo die Samenfäden mit dem Ei in Berührung kommen.

Da nur diese Gegend der weiblichen Geschlechtstheile für die Untersuchung von Werth ist, so können die Eierstöcke mit den Eileitern und andererseits die vor der Scheide befindlichen Theile mit den Chitinhäuten, welche die Eikapsel umtassen, übergangen werden. Es kommt also nur die Scheide zur Beachtung.

Die Scheide besteht aus drei Haupttheilen, von denen zwei in der Richtung der längsachse des Thieres nebeneinander liegen und das dritte sich beiden gegeniber befindet. Zwischen jenen einerseits und diesen andererseits muss das Ei seinen Weg nehmen. Die drei Stücke sind in Fig. 1 mit $A, B$ und $C$ bezeichnet. Das voldere, erste Stiuck (Fig. $1 A$ ) ist ganz, das hintere, zweite (Fig. $1 B$ ) nur in seinem vorderen Theile abgebildet; eine vollständige Ansicht ist auch von dem dritten (Fig. $1 C$ ) vorhanden.

1) Zwar giebt es in der Literatur verschiedene Beschreibungen von den weiblichen Geschlechtsorganen der Blattiden, doch sind dieselben für unsere Zwecke unzureichend. Vgl. besonders: Cornelius, Beiträge zur nähern Kenntniss von P. orientalis, Elberfeld 1853; Brunner von Wattenwyl, die morphol. Bedeutung d. Segmente bei den Orthopteren. Festschrift d. zool.bot. Ges. in Wien 1876; Lacaze-Duthiers, Recherch. sur l'amure génitale femelle d. insectes orthoptères. Annal. d. scienc. nat. Sér. III, Zool. T. XVII, 1852 (Blatta americana, Taf. 11, Fig. 1-5') L éon Du four, Recherch. anatom. et physiol. sur les orthopt., hyménopt. et les neuropt. Mémoires présentés par divers savants à l'acad. royale d. scienc. etc. (scienc. mathémat. et physiq.) T. VII, 1841 (weibl. Geschlechtstheile v. Blatta orientalis Taf. 5, Fig. 47). 
$A$ und $B$ liegen im Thiere so, dass die in der Zeichnung uns zugewendete Fläche der Bauchseite zugekehrt ist, während jene Fläche des Stückes $C$ nach dem Rücken schaut.

Das erste Stück (Fig. $1 A$ ) wird aus zwei seitlichen Schenkeln und einem stark gewölbten mittleren Theile $e$ zusammengesetzt. Zwischen jenen und diesem (e) liegt bei $j$ ein helnförmiger Wulst, welcher die Mündung des Samenganges enthält. Die Samentasche liegt also auf derjenigen Seite von $A$, welche in der Zeichnung dem Beschauer abgewendet ist und ist demnach im Thiere nach oben (nach der Rückenseite) zugekehrt. Die helmförmige Gestalt des Wulstes ist aus Fig. 6 und Fig. $2 j$ (optischer Längsschnitt) zu erkennen. Hier (Fig. 2) bedeutet $i$ die Ausmündung des Samenganges, aus welcher sich die Spermatozoen ergiessen (vgl. Fig. 6). Wenn auch fast die ganze Oberfläche von $A$ (mit Ausnahme von $e$ ) mit Haaren besetzt ist, so fallen diese doch am meisten in dem Bezirk von $j$ auf, denn hier umgeben sie dicht gedrängt und von borstenförmiger Stärke den Ausmündungswulst. Im Vergleich zu der Behaarung (die schwarzen Punkte in Fig. I $A$ und $B$ zeigen die Behaarung an) dieser Gegend tritt diejenige der Schenkel ganz zuriek.

Je nachdem ein Längsschnitt das Stück $A$ in der Mittellinie trifft, so dass also der Ausmündungswulst $j$ halbirt wird, oder seitlich davongeht, erbält man den Grundriss $c c^{\prime} i e e^{\prime}$ in Fig. 2 oder $c c^{\prime \prime} e e^{t}$ in Fig. 3. In dem letzten Falle wird der Wulst $j$ gar nicht geschnitten. Die Strecke $c c^{\prime}$ in Fig. 2 entspricht derjenigen, welche in Fig. $1 A$ von dem Wulst $j$ bis zur Spitze des Einschnittes $c$ reicht ${ }^{1}$ ). In Fig. 3, wo der mehr seitlich gefïhrte Längsschnitt zur Anschauung kommt, ist $c c^{\prime \prime} e$ ein Schnitt ${ }^{2}$ ) eines Schenkels (Fig. $1 A$ ), wobei der Buckel $c^{\prime \prime} e$ der nach $e$ abfallenden Wölbung jenes entspricht. Der durch die Mittellinie von $A$ gelegte Schnitt schneidet $e$ (Fig. $1 A$ ) in der Linie $e e^{t}$, Fig. 2; der seitliche in $e e^{t}$, Fig. 3.

Das zweite Stück (Fig. $1 B$; nur der vordere Theil ist gezeichnet) ist mit dem eben beschriebenen (Fig. $1 A$ ) durch eine dünne Chitinhaut verbunden, wie dieses aus den beiden Längsschnitten Fig. 2 und 3 ef hervorgeht. An diesem Stücke $B$ ist der

1) In Fig. $1 \mathrm{~A}$ ist die Entfernung von $j$ bis $c$ zu gross ausgefallen.

2) Es ist nicht eigentlich ein Längsschnitt, sondern ein schräger Schnitt. Jener müsste von $c$ (Fig. 1 A) in die Gegend von $c^{\prime \prime \prime}$ gehen. 
vordere (in Fig. $1 B$ abgebildete) Theil breit und gewölbt; der hintere besteht aus zwei Paar Scheidenstïcken, welche sich in Fig. $1 B$ an $d$ anschliessen und in Fig. 5 mit $d$ bezeichnet sind ${ }^{1}$ ). Ausserdem ist noch ein drittes Paar vorhanden (Fig. $5 q$; Fig. $5 B$ entspricht Fig. $1 B$ ), welches an $B$ (Fig. 1) in der Gegend von $c^{\prime \prime \prime}$ befestigt ist. In dem Winkel, welchen die beiden Schenkel $d$ (Fig. 1 und 5) bilden, münden die Kittdrïsen ${ }^{2}$ ) aus.

Der breitrückige, vordere Theil von $B$ ist vorn, da wo er an $A$ grenzt, mit starken, dichtstehenden Borsten besetzt (wie $A$ bei $j$ ). Fig. $2 f^{\prime \prime}$ giebt einen in der Mittelebene geführten, Fig. $3 f^{\prime \prime}$ einen seitlichen Längsschnitt dieser Gegend wieder. Fig. $7 f^{\prime}$ ist ein dicker, stark vergrösserter Längsschnitt derselben, bei dem aber nur eine geringe Anzahl von Haaren gezeichnet ist.

Das dritte Stiick (Fig. $1 C$ ) ist trapezförmig; die beiden Längsseiten $(b)$ verlängern sich nach der einen Seite zu in zwei Hörner. Die Mitte $(t)$ wird von einer weichen weisslichen Chitinbaut ausgefiullt, welche durch einen Schlitz $(g)$ balbirt wird. Durch diesen Schlitz gelangen die Eier in die Scheide; nämlich an der in Fig. $1 C$ abgekehrten Seite setzen sich die Eileiter an und münden in den Sehlitz ${ }^{3}$ ).

Es wurde oben gesagt, das dritte Stuick (Fig. $1 C$ ) liege den beiden andern $(A$ und $B$ ) gegenüber. Dieses ist folgendermaassen zu verstehen. $C$ breitet sich wie eine Klappe mit der in Fig. 1 sichtbaren Fläche (auf der entgegengesetzten, in der Zeichnung abgekehrten miunden die Eileiter) über $A$ und $B$ aus. Wenn man in Fig. 1 das Stick $C$ zwischen den parallelen Linien dem Stück $A$ nähert und ersteres um den Rand von $b$ (als Achse) um $180^{\circ}$ dreht (umklappt), so wird $C$ auf $A$ geklappt und erhält seine natirliche Lage. In dieser sind $C$ und $A$ also zusammengeklappt wie zwei Blätter eines Buches. Da der Rand $c$ des Stückes $C$ (Fig. 1) mit dem gleichnamigen Rand von $A$ (Fig. 1) fest verbunden ist, so schmiegt sich $C$ in seinem vorderen Theile ziemlich dicht an $A$ an, während zwischen dem hinteren Theile beider Stuicke ein grösserer Abstand ist, zumal da $C$ in seinem hinteren

1) Aus Fig. $5 d$ geht es nicht hervor, dass jederseits zwei Scheidenstücke vorhanden sind, denn $d$ ist einfach gezeichnet.

2) Dieselbe liefert das Sekret zur Bildung der Eierkapsel.

3) Das unpaare Stilck, zu welchem sich sonst bei den Insekten die Eileiter vereinigen, ist bei Periplaneta versehwindend klein. 
Theile gewölbt ist. Ausserdem ragt $C$ auch etwas iber den vordern Theil von $B$ hinweg. Die Längsseiten $b$ in Stück $C$ (Fig. 1) and ibre Hörner sind durch Chitinhäute an die starken Chitinstücke o, Fig. 5 befestigt, welche sich von oben her dem Stïck $B$ anlagern. Dadurch wird also auch seitlich der von $A$ und $B$ einerseits und von $C$ andererseits gebildete Raum geschlossen. Es bleibt demnach nur die hintere Seite offen, und hier treten dann die Eier aus. Hinein kommen sie in den Raum ja, wie schon erwähnt, durch den Sehlitz $g$ in $C$ (Fig. 1).

Legt man durch die Scheide einen Schnitt, der die drei Stücke $A, B$ und $C$ der Länge nach durchschneidet, so erhält man je nachdem der Schnitt durch die Mitte oder seitlich bindurchgeht, ein verschiedenes Bild. Für $A$ und $B$ baben wir es schon kennen gelernt. Trifft der Schnitt die Mittelebene der Scheide, so durchsehneidet er auch $C$ in der Mittellinie. In diesem Falle wird von dem Chitinstiick, welches zwischen dem Rande $c$ und zwischen dem Mittelfelde $t$ liegt (es stossen hier die beiden hier $-k$ - verbreiterten Ränder $b$ zusammen), nur ein kurzes Stiick getroffen, denn in der Mittelllinie nähert sich $t$ am meisten dem Rande $c$. Einen mittleren Schnitt giebt Fig. 2 an. Hier ist das erwähnte kurze Stiick von $C$ die Linie $c b$. Den hinteren Rand von $C$ (Fig. $10, l$ ) muss der Schnitt quer durchschneiden. Fig. $2 l$ giebt diesen Querschnitt wieder. Zwischen $l$ und $b c$ in Fig. 2 müsste der (mittlere) Längsschnitt von $t$ (Fig. $1 C$ ) liegen. Derselbe ist aber nicht angegeben, weil ein aus dem Schlitz herauskommendes Ei (Fig. $2 a$ ) die dûnne Haut des Mittelfeldes $t$ bei Seite drängt. Es kann daher $t$ von jenem Schnitte gar nicht getroffen werden, sondern anstatt seiner wird das Ei durchschnitten. Es könnte auffallen, dass $l$ nicht in der Verlängerung von $b c$ liegt. Dieses kommt aber daher, weil sich das Stiick $C$ in seinem hinteren Theile krümmt.

Geht der Schnitt nieht durch die Mittelebene der Scheide, trifft er daher auch $C$ nicht in der Mittellinie, sondern seitlich, so wird auch von dem Stück, welches in $C$ (Fig. 1) zwischen $c$ und $t$ liegt, eine grössere Strecke $(k)$ durchschnitten, als es vorher der Fall war. Einen derartigen Schnitt zeigt $b c$ in Fig. 3. Der Durchschnitt der übrigen Theile von $C$ ist in Fig. 3 nicht wiedergegeben ${ }^{1}$ ).

1) $a^{\prime} a^{\prime \prime}$ ist ein Stück von dem Rand des austretenden Fies (Fig. 2a). 
Ueber Gesetzmässigkeit in der Ortsveränderung der Spermatozoen etc. 379

Es ist schon erwähnt, dass die von $A$ und $B$ in Fig. 1 abgebildete Seite dem Bauche des Thieres zugekehrt ist. Desshalb muss nach dem Gesagten die in Fig. 1 dargestellte Fläche von $C$ der Riüekenseite zugewendel liegen. Geht man nun im Thiere von unten nach oben, so bemerkt man folgende Reihenfolge: 1) diejenige Seite von $A$ und $B$, auf welcher die Samentasche, 2) auf welcher die Ausmündung des Samenganges (Wulst $j$, Fig. $1 A$ ) liegt, 3) diejenige Seite von $C$, auf welcher der Schlitz $g$ sich befindet, 4) anf welcher die Eileiter einmünden. Fig. 5 zeigt daher die Scheide und die Eileiter in umgekehrter Lage. Es wird hier Stüek $A$ durch $C$ verdeckt and $C$, von dem nur der Rand $l$ (entspricht $l$ in Fig. $1 C)$ sichtbar ist, durch die Eileiter $(a)$, in denen sich gerade je ein Ei befindet. An $p$ schliessen sich die Eierstöcke an.

Da jetzt das Nöthige über den Bau der weiblichen Geschlechtsorgane gesagt ist, kann ich mich über die Verbältnisse anslassen, welche bei dem Zusammentreffen der Spermatozoen mit dem Ei obwalten. Dazu ist es am besten, wenn wir das Ei auf seinem Wege begleiten.

Das im Eileiter bohnenförmig gebogene Ei nimmt dort eine solche Lage ein, dass seine convexe Seite nach der Achse des Thieres gerichtet ist. Da sich beim Eierlegen des Insekts in jedem Eileiter gleichzeitig ein $\mathrm{Ei}$ befindet, so kehren also beide Eier einander die convexe Seite zu (Fig. 5 a). Beim Hineinschlitpfen in die Scheide muss aber eine Drehung stattfinden, denn in jener ist die bezeichnete Seite nach oben gekehrt, liegt also dem Theil $A$ und $B$ (Fig. 1) an. Wenn das Ei den Eileiter verlässt, so nimmt es, wie schon erwähnt, seinen Weg durch den Schlitz $g$ (Fig. $1 C$ ). Fig. 2 giebt an, wie von einem $\mathrm{Ei}(a)$ schon die Hälfte heransgekommen ist ${ }^{1}$ ).

Da der Bezirk der Mikropylen auf der convexen Seite des Eies in der Nähe des vorderen Poles zu suchen ist, so muss jener Bezirk uber die Ausmündung des Samenganges (Fig. 2 i) hinstreichen und zweitens zuletzt aus dem Schlitz von $O$ hervorkommen (wie der betreffende Pol).

An und für sich wäre es leicht diese Verhältnisse festzustellen. Man brauchte sich nur an einem durch die Scheide hin-

1) $l$ bezeichnet ja den hintern Rand und $b c$ den vordern Theil von $C$. 
durchgehenden $\mathrm{Ei}$ nach jeder Richtung hin die Lagerung desselben in jener zu merken, dann das Ei herauszunehmen und den Mikropylenbezirk aufzusuchen. Doch die Jahreszeit und der Mangel an geeignetem, gehärtetem Material (wo sich ein Ei gerade in der Scheide aufhält; solche Stïcke waren schon verbraucht) machte es mir unmöglich, diesen Weg einzuschlagen, und ich gelangte auf andere Weise zum Ziele. Nachdem ich an gehärteten Eiern ermittelt hatte, dass die Mikropylen anf der convexen Seite derselben und zwar in der Nähe eines Poles liegen, durchmusterte ich meine Schnittpräparate, bei denen der Sehnitt ein in der Scheide anwesendes $\mathrm{Ei}$ getroffen hatte. Da diese Längsschnitte etwas dick sind, so steht die durehschnittene Eihaut nicht überall senkrecht zum Objektträger, sondern hatte sich an vielen Stellen tungelegt. Bei solchen Präparaten konnte ich feststellen, dass die Mikropylen erstens der Seite von $A$ (Fig. 2) zugekehrt waren und zweitens sich in der Nähe des vordern Poles befanden. Aus diesen Beobachtungen an den Schnitten und an dem losen Ei folgen alle Angaben, die ich bisher über die Lagerung des Eies in der Scheide, über diejenige der Mikropylen auf dem Ei und in der Scheide gemacht habe.

Die Lage der Mikropylen am Ei der Schabe ist also dieselbe wie an den Eiern anderer Insekten, d. h. am oder in der Nähe des vorderen Poles. Welches mag wohl die Bedeutung dieser Thatsache sein? Weshalb haben wir bei den Insekteneiern die Mikropyle oder die Mikropylen in der Regel nicht in der Mitte oder am hintern Pole zu suchen? Diese Frage will ich an Periplaneta zu beantworten versuchen. Um aber dieses zu thun, muss ich zuerst auf die Bedeutung der auf den Stiucken $A$ und $B$ befindlichen Haare eingehen.

In die Haare, welche hauptsächlich in der Umgegend der helmförmigen Ausmündung des Samenganges (Fig. $1 A j$ ) und auf dem vordern Theil von $B$ (Fig. $1 B$; Fig. 2,3 und $7 f^{\prime}$ ) stehen, gehen dünne, lichtbrechende Fäden hinein. Diese ziehen sich durch die Weichtheile, welche die Chitinhaut von $A$ und $B$ bedecken, hindurch, gehen an die Chitinhaut heran, legen sich an diese an und laufen in das Haar hinein. Die lichtbrechende Masse scheint sich durch das Haar hindurch zu ziehen. Allem Anschein nach hat aber nicht jedes Haar seinen eigenen, aus den weichen Theilen kommenden Faden, sondern ein soleher scheint sich unter 
Ueber Gesetzmässigkeit in der Ortsveränderung der Spermatozoen etc. 381

der Chitinhaut za verzweigen und erst ein Zweig in das Haar einzutreten.

Diese Fäden halte ich für Nervenfasern. Allerdings habe ich die zugehörigen Ganglienkugeln nicht auffinden können; die ausserordentliche Stärke der Chitinhaut der Scheide stellt nämlich histologischen Untersuchungen grosse Schwierigkeiten entgegen. Ueberdies gehören diese Verhältnisse nicht unmittelbar zu unserm Gegenstande, so dass ich eine weitere Verfolgung derselben vorläufig aufgab. Nach meiner Ansicht haben die Fäden nun die Aufgabe eine Verbindung herzustellen zwischen den Haaren und den Muskeln der Samentasche ${ }^{1}$ ). Wenn daher ein Ei durch die Scheide geht und über die Haare hingleitet, so werden die Muskeln der Samentasche gereizt, sie ziehen sich zusammen, und es wird aus der Mündung des Samenganges Sperma herausgeschleudert. Das Ei würde also sozusagen selbst der Samentasche mitheilen, dass das Ausstossen von Spermatozoen nothwendig ist.

Diese Auffassung wurde in mir befestigt dureh die Durchsicht der Abbildungen des Stein'schen Werkes iuber die weiblichen Geschlechtsorgane der Käfer ${ }^{2}$ ). Nach Stein kommen Haare uberall in den Leitungswegen der weiblichen Geschlechtsorganen der Käfer vor; ihre Anordnung mit Rücksicht auf die Lage der Samengangsmündung ist nach seinen Abbildungen eine derartige, dass die ansgesprochene Ansicht durchaus bekräftigt und durch dieselbe erst verständlich wird.

Nach der ausgesprochenen Annahme ist es auch erklärlich, warum sich die Mikropylen bei den Insekteneiern meistentheils an dem vordern Pol befinden, weshalb sie also möglichst zuletzt erscheinen bei dem Eintritt des Eies in die Scheide. Das Ei tibt durch die Vermittelung der Haare einen Reiz auf die Muskeln der Samentasche aus, auf welchen Samenmasse hervorquillt. Wtirden dabei die Mikropylen (oder die Mikropyle) in dem zuerst hervorkommenden Theile des Eies oder gar an der Spitze des betreffenden Poles liegen, so würde zwar der Reiz auch hervorgerufen, aber die Mikropylen

1) Andererseits, glaube ich, gehen Fäden auch zu der Kittdrüse. Auch Leydig (der Eierstock und die Samentasche der Insekten. Nova Acta Bd.XXXIII, 1866, S. 31 u. 39) erwähnt an der Samentasche Nerven.

2) Stein, vgl. Anatomie und Physiologie der Insekten (die weiblichen Geschlechtsorgane der Käfer) 1847. 
wären schon an der Mündung des Samenganges vorïber, wenn hier die Spermatozoen erschienen. Da aber die Mikropylen in dem hintersten Ende des Eies liegen und der nöthige Reiz durch die vordern und mittlern Theile desselben ausgelöst wird, so erhalten die Mikropylen rechtzeitig die Spermatozoen, bez. finden sie sie schon vor.

Nach dieser Abschweifung will ich das $\mathrm{Ei}$ anf seinem Wege durch die Scheide weiter verfolgen. In dem klappenförmigen Stück $C$ ist für den Durchgang des Eies der Schlitz $g$ (Fig. $1 C$ ) eng ${ }^{1}$ ), so dass das $\mathrm{Ei}$ gezwungen ist, sich hindurch zu zwängen. Hierdurch wird $C$ mit seinem vordern Theil gegen das Stück $A$ gedrängt. Dabei ist die Lage des Wulstes, auf welchem der Samengang ausmïndet, und die Gestalt der beiden Längsseiten $b$ (es kommt besonders auf die Theile der Längsseiten an, welche mit $k$ bezeichnet sind) in Stück $C$ (Fig. 1) so beschaffen, dass der Wulst in den von $k$ gebildeten Winkel zu liegen kommt und also seitlich und vorn umschlossen wird. Der Wulst ist aber von starken Borsten dicht umgeben und auf diese presst das Ei die vordern Theile des Randes von $C$, wobei gewiss noch Muskel thätig sind, die sich an diesen Orten in grosser Zahl finden. Da nur wenige Haare vor dem Wulste, die allermeisten vielmehr seitlich von ihm liegen, so sieht man bei einem Medianschnitt der Scheide (Fig. 2) wenige oder gar keine Haare unter dem durchschnittenen Rand ron $C$ (Fig. $2 b c$ ); man nimmt sie aber bei einem seitlichen Schnitt in grosser Anzahl war. So ist in dem Schnitte Fig. 3 die ganze Strecke $c^{\prime \prime} c$ mit ihnen besetzt (nicht gezeichnet!), und man sieht, wie sie von $b c$ (entspricht hier $k$ in Fig. 1 C) niedergedrickt sind ${ }^{2}$ ).

Der weitere Hergang vollzieht sich meiner Ansicht nach in der Weise, dass die in die Haare einmündenden Nerven den Reiz weiter fortpflanzen, bis dieser schliesslich die Muskeln erreicht, auf deren Zusammenziehung hin die Spermatozoen zur Oeffnung $i$ in Fig. 3 heransgepresst werden. Gleitet dann später derjenige Theil des Eies, auf welchem der Bezirk der Mikropylen liegt, tiber $j$ bez. $i$ hinweg, so treffen die Mikropylen mit den Spermatozoen

1) In Fig. 2 geben $l$ auf der einen und $b c$ auf der andern Seite die Weite (Länge) des Schlitzes an.

2) $a^{\prime} a^{\prime \prime}$ ist ein Stück von dem Rand des Eies. 
Ueber Gesetzmässigkeit in der Ortsveränderung der Spermatozoen etc. 383

zusammen. Dabei werden diese gewiss sowohl unmittelbar auf die Oberfläche des Eies ergossen, als auch in den Raum, der sich zwischen $A$ und $B$ befindet (Fig. 2 und $3 h$ ). Der vordere Theil von $B$ nämlich (Fig. 2 und $3 f^{\prime}$ ) und der hintere von $A$ (Fig. $1 e=$ Fig. 2 und $3 e e^{i}$ ) werden, wie es Fig. 2 und 3 angiebt, dicht aneinandergepresst. Dieses ist um so leichter zu bewerkstelligen, als die Verbindung jener Theile (Fig. 2 und $3 e^{\prime} f$ ) eine dïnne, biegsame Chitinhaut ist, welche sich leicht faltet.

Dieser Raum $h$ ist aber nicht nur für die Aufnahme der Spermamassen geeignet, so dass das Ei über dieselben hinstreichen kann, sondern es gewährt auch noch einen andern Nutzen. Sollen sich nämlich die Spermatozoen auf der Fläche des Eies bewegen, so ist es wünschenswerth, dass diese Fläche nicht gegen eine andere gedrückt, sondern den Spermatozoen Spielraum für ihre Bewegung gelassen wird. Dieses ist der Fall, wenn das Ei über die Grube $h$ gleitet.

Um das Hindurchgehen des Eies durch die Scheide zu beobachten, habe ich weiblichen Thieren, welche beim Eierlegen begriffen waren, den Hinterleib abgeschnitten, die Scheide mit den Eierstöcken vorsichtig herauspräparirt und das Präparat in conc. Sublimatlösung gebracht. Dabei glückte es in vielen Fällen, dass das heraustretende $\mathrm{Ei}^{1}$ ) aus seiner Lage in der Scheide nicht verrückt wurde. Von solchen Präparaten besitze ich einige Längsschnitte, bei denen man den Austritt der Spermamasse aus der Mündung des Samenganges wahrnehmen kann. Bei den einen ist der Hals mit Spermatozoen vollgepfropft, bei andern liegt im Raume $h$ (Fig. 2 und 3) dicht an der Eihaut ein Klumpen von Samen, bei einem endlich habe ich das Thier gerade in dem Augenblick getödtet, als der helmförmige Höcker Spermamasse wie ein Vulkan auswarf (Fig. 6).

Nicht genug, dass das Ei die Haare in der Nähe des helmförmigen Wulstes reizt, es trifft solche auch noch jenseits der

1) Das Heraustreten des Eies und der Durchgang durch die Scheide scheint langsam vor sich zu gehen. Dieses sieht man schon äusserlich an dem langsamen Wachsen des Eiersackes. Deshalb sind auch die obigen von mir bei den Eiern gebrauchten Ausdrücke wie „Durchschlüpfen" u. s. w. ungenau. Dass aber ein langsamer Durchgang der Eier durch die Scheide für das Hineingelangen der Spermatozoen in die Mikropyle von grossem Nutzen ist, liegt auf der Hand. 
Grube $h$ (Fig. 2 und 3), auf dem vordern Theil von $B$ (Fig. 2, 3 and $7 \mathrm{ff}^{\prime}$; Fig. $1 \mathrm{~B}$ ). Während es aber dort nur mittelbar auf die Haare drückt, berührt es hier dieselben unmittelbar. Man nimmt dabei wahr, wie sich diese unter der Last niederbengen (Fig. 7, rom Ei ist nur ein Stück der Haut, $a^{\prime} a^{\prime \prime}$, gezeichnet). Allerdings gehen die von diesen Haaren auslaufenden Fasern wohl zum grössten Theil oder ausschliesslich zu den Kittdrüsen.

Ich habe den auf $B$ (Fig. 2, 3 und $7 \mathrm{ff}^{\prime}$ ) befindlichen Haaren ebenso wie denen auf $A$ die Rolle von Sinneshaaren zugeschrieben; andererseits aber ist es anch offenbar, dass sie das Ei hindern, sich dicht an die Oberfläche der Chitinhaut anzulegen. Dadurch wird den Spermatozoen, wenn sie noch nicht vorher in die Mikropylen gelangt sind, noch in diesem Theile der Scheide Gelegenheit gegeben, auf der Oberfläche des Eies zu kreisen.

Aus der angegebenen Bahn kann das Ei nicht heraus, denn seitwärts wird es von den Scheidentheilen $q$, Fig. 5 gehalten und von oben durch den gebogenen Rand von $C$ (Fig. 2l, Fig. $1 C, l$ ) fest nach unten gedrückt, besonders in der Gegend der Grube $h$ (Fig. 2 und 3).

Dieser Abschnitt, in welchem der Bau der Scheide und der Durchgang des Eies durch dieselbe besprochen ist, sollte zur Prïfung dessen dienen, was ich über das Hineinfinden der Spermatozoen in die Mikropylen gesagt habe. Ich bin jetzt der Ansicht, dass es in den eben geschilderten Verhältnissen nicht nur nichts giebt, was jenem widerspricht, sondern dass sich vielmehr alles mit ihm in Uebereinstimmung befindet. 
Ueber Gesetzmässigkeit in der Ortsveränderung der Spermatozoen etc. 385

\section{Erklärung der Abbildungen anf Tafel IV.}

(Jede Abbildung ist nach einem bestimmten Präparat gezeichnet.)

Fig. 1. $A, B$ und $C$ Stücke der Scheide. Fig. $1 A$. $c$ vorderer Rand. $j$ Ausmündungswulst des Samenganges. $e$ hinterer stark gewölbter Theil. - Fig. $1 B$. $c^{\prime \prime \prime}$ Ansatzstelle des einen Paares der Scheidestïcke (Fig. $5 q$ ), $d$ der beiden andern (Fig. 5.d). - Fig. 1C. $c$ vorderer, $l$ hinterer Rand, $b$ seitlicher Rand, $k$ dessen vorderer Theil, $t$ mittleres Feld, $g$ Schlitz in demselben.

Fig. 2. Mittlerer Längsschnitt durch die Scheide, in der sich gerade ein Ei befindet. $a \mathrm{Ei}, l$ hinterer, $b c$ vorderer Rand von $C . \quad c c^{\prime} e e^{\prime}=A$. $f f^{\prime}=B$ (vorderer Theil). $e^{\prime} f$ Verbindungshaut zwischen $A$ und $B$. $h$ Vertiefung zwischen $A$ and $B . j$ Ausmündungswulst des Samenganges, $i$ Mündung des letztern.

Fig. 3. Seitlicher Längsschnitt durch die Scheide. $a^{\prime} a^{\prime \prime}$ eine Strecke von dem Rand des Eies. $c c^{\prime \prime} e e^{\prime}$ entspricht $c c^{\prime} e e^{\prime}$ in Fig. 2. Das Uebrige wie in Fig. 2.

Fig. 4. Ein Stück der Eihaut mit Mikropylen. $h p$ Richtung des hintern Poles des Eies.

Fig. 5. In umgekehrter Lage befindliche Scheide mit den daran sitzenden Eileitern. a Eileiter, in denen sich gerade je ein Ei befindet. $p$ Ansatzstelle der Eierstöcke. $l$ hinterer Rand von $C$. $q$ das eine, $d$ die beiden andern Paare der Scheidentheile.

Fig. 6. Ausmündungswulst des Samenganges. Aus der Mündung werden gerade Spermatozoen herausgeschleudert.

Fig. 7. Ein dicker Schnitt des vordern Theiles von $B\left(f f^{\prime}\right)$. Von den auf diesem vorhandenen Haaren sind mehrere gezeichnet. Von dem über die Haare gehenden $\mathrm{Ei}$ ist nur ein Stück der Haut $\left(a^{\prime} a^{\prime \prime}\right)$ angegeben. 
Archiv f. d. ges, Physiologie 30 XXxVlil.

Ta: $1 !$

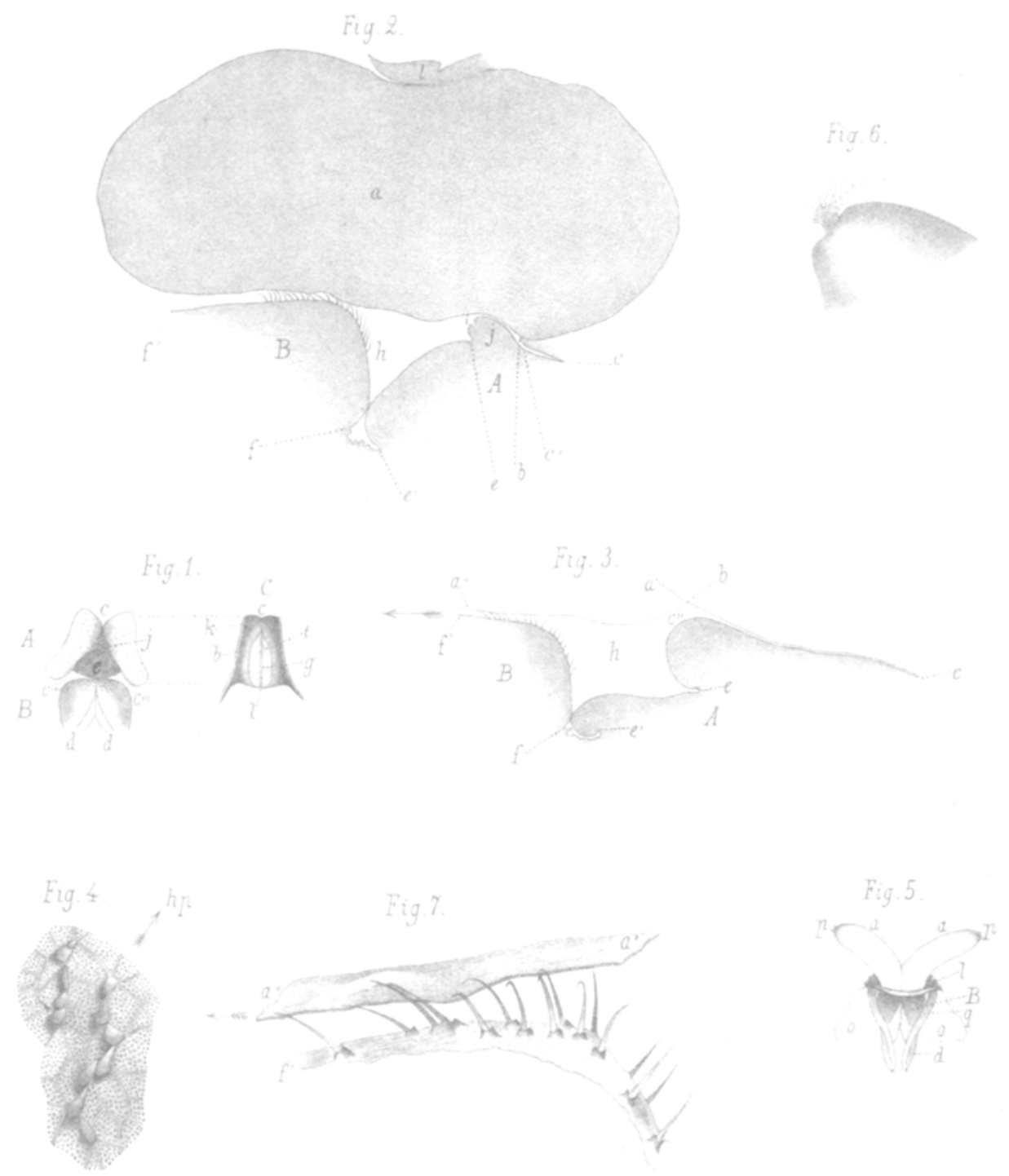

Veriag von Emil Struuss, Bona.

J. Dewitz gez.

Eth.inst.uA. Aenry, Bonn. 